African Journal of Pharmacy and Pharmacology Vol. 6(47), pp. 3242-3245, 22 December, 2012

Available online at http://www.academicjournals.org/AJPP

DOI: 10.5897/AJPP12.188

ISSN 1996-0816 @2012 Academic Journals

Full Length Research Paper

\title{
Clinical efficacy of cefixim compared to amoxicillin- clavulanate in community acquired pneumonia treatment
}

\author{
Nader Zarinfar $^{1 *}$, Hossein Sarmadian ${ }^{1}$ and Akram Esmaeili ${ }^{2}$ \\ ${ }^{1}$ Department of Infectious Disease, Arak University of Medical Sciences, Arak, Iran. \\ ${ }^{2}$ Graduate of General Physician, Arak University of Medical Sciences, Arak, Iran.
}

Accepted 19 December, 2012

\begin{abstract}
Due to the lack of availability of respiratory fluoroquinolones, treatment using amoxicillin- clavulanate is recommended for community acquired pneumonia (CAP) in Iran. Cefixime offers advantages such as lower cost and improved patients compliance. The current study was designed to compare the therapeutic effects of amoxicillin- clavulanate and cefixime in patients with CAP. In a randomized controlled trial, 280 inpatients with CAP were randomized to receive either amoxicillin- clavulanate or cefixime $(n=140)$. Clinical signs, symptoms and chest radiography reports of patients were compared between two groups on the first visit and weeks two and four after treatment. Cure was defined as resolution of signs and symptoms in the first week and resolution of chest $x$-ray infiltration in the 4th week. Improvement was defined as resolution of fever on 1st and 2nd day, cough and sputum on 4th to 5th day and lung consolidation sounds in the first week. Sever and complicated CAP were excluded and considered as side effects. The amoxicillin- clavulanate group had more patients with cough in the 2 nd and 4th week ( $p=0.008$ and 0.001 , respectively), sputum and infiltrate on chest $x$-ray in the 4th week ( $p$ $=0.008$ and 0.004 , respectively) compared to cefixime. Clinical status at the end of the treatment showed cure $(71.25 \%)$, improvement $(24.61 \%)$ and side effects $(3.87 \%)$ in the cefixime group and 66.67 , 30.07 , and $3.26 \%$, respectively in the amoxicillin-clavulanate group [p = non-significant (NS)]. In our study, cefixime was more effective than amoxicillin-clavulanate in resolution of signs and symptoms of CAP. Cefixime may be an option for the treatment of CAP in countries with limited drug options.
\end{abstract}

Key words: Community acquired pneumonia (CAP), cefixim, co-amoxiclave, community acquired pneumonia, switch therapy.

\section{INTRODUCTION}

Community-acquired pneumonia (CAP) is a potentially serious illness that is defined as an acute infection of the pulmonary parenchyma in a patient who has acquired the infection in the community (File et al., 2011). CAP can be caused by a variety of pathogens; hence antimicrobial

${ }^{\star}$ Corresponding author. Email: zarinfar@arakmu.ac.ir. Tel: +988612235605. Fax: +988612235605. treatment is essential and lifesaving (Austrian and Gold, 1964). Because of insufficient specificity of the clinic radiography findings (File et al., 2011) to determine etiology of the CAP and some technical difficulties in identifying the atypical pathogens by means of culture or serologic testing (File et al., 1998), antibiotic therapy is begun based on empiric therapy with regards to common pathogens such as streptococcus pneumonia (Mandell et al., 2007).

Several studies have been published concerning 
treatment for CAP. Common antibiotics used for CAP include the cephalosporins, aminopenicillins (with or without clavulanic acid), the macrolides, the tetracycline, and the respiratory fluoroquinolones (Nicolau et al., 2000). Due to drug limitations and lack of respiratory fluoroquinolones in our country, Iran, treatment using amoxicillin- clavulanate for 14 days is recommended for CAP in our hospitals. Cefixime offers advantages such as once daily dosing, lower cost and appropriate spectrum of activity. This study was designed to compare the therapeutic effects of amoxicillin-clavulanate and cefixime in inpatients with CAP.

\section{MATERIALS AND METHODS}

This randomized triple-blind controlled clinical trial was conducted in Vali Asr Hospital of Arak, Iran. All patients, aged 15 years or older who hospitalized for CAP and candidate for transition from intravenous (IV) to oral therapy, were considered eligible for the study. Pneumonia was defined as a new infiltration on Chest $x$-ray (CXR) with symptoms consistent with pneumonia, including cough, sputum, fever $\left(>38.3^{\circ} \mathrm{C}\right)$ and abnormal sound in pulmonary auscultation (such as rales, rhonchi and wheezing).

Inpatients had received cefteriaxone $1 \mathrm{~g}$ (IV), twice a day and azithromycin $500 \mathrm{mg}$ on day one, followed by $250 \mathrm{mg}$ daily azithromycin for 4 days. Transition from IV to oral therapy was considered $48 \mathrm{~h}$ after improvement in patient's severe clinical situation based of physician preference. Immunosuppressed (postsplenectomy, corticosteroid or other immunosuppressive medication for more than 30 days or neutropenic condition) or Human immunodeficiency virus (HIV) positive patients, or who had a history of allergy to $\beta$-lactam drugs and patients with complicated pneumonia such as empyema were excluded. From June 1, 2007 to August 29, 2008, 280 patients fulfilled the inclusion criteria and were enrolled in the study. Cure was defined as resolution of signs and symptoms in the first week and chest $x$-ray infiltration in the 4th week; Improvement was defined as resolution of fever on days 1 to 2 , cough and sputum on days of 4 to 5 and lung consolidation sounds in the first week. Sever and complicated CAP were excluded and considered as side effects.

This study was ethically approved by the research ethical committee of the Arak University of Medical Sciences. Written informed consent was obtained from all patients or their relatives before the trial.

All of the enrolled patients were randomized to receive amoxicillin- clavulanate $625 \mathrm{mg}$ three times daily $(\mathrm{n}=140)$ or cefixime $400 \mathrm{mg} /$ day $(\mathrm{n}=140)$ and two amoxicillin-clavulanate like placebo capsules. In our country, cefixime and amoxicillinclavulanate are similar in shape and packaging. Demographic characteristics, clinical signs and symptoms of pneumonia and chest radiography report of each patient were recorded in the first visit. Clinical improvement and CXR findings were compared between two groups on the first admission date, 2nd and 4th week after treatment initiation.

All statistical analyses were performed with Statistical package for the social sciences (SPSS) software 16. Descriptive statistics of demographic and clinical variables included frequencies, percentages, means and standard deviations (SD). Comparisons of variables between groups were performed using the Chi-squared test for categorical variables and t-test for normally distributed data. A two-tailed $p$-value $<0.05$ was considered statistically significant. This trial was approved in Iranian Registry of Clinical Trials (IRCT) as: IRCT201111186056N4.

\section{RESULTS}

In all studied patients, $150(53.6 \%)$ were male. The mean age (SD) was 49.58 ( \pm 17.63 , range: 17 to 86 ). There was no significant difference between the two groups as regards age, sex and initial clinical evaluation $(p>0.05$ (Table 1). Clinical status and CXR findings were compared in the 2nd and 4th week after oral antibiotic administration (Table 2). The number of patients who had cough in the 2nd and 4th week after treatment was significantly higher in the amoxicillin-clavulanate group compared with the cefixime group, (87 versus $63, p=$ 0.008 and 42 versus $17, p=0.001$, respectively). Statistically significant, more patients in the amoxicillinclavulanate group had sputum production $(p=0.008)$ and unclear CXR infiltration $(p=0.004)$ in 4th week after treatment, compared with the cefixime group (25 versus $13, p=0.008$ and 49 versus $27, p=0.004$, respectively). Clinical status at the end of the treatment showed cure, improvement and side effects in 71.25, 24.61, and $3.87 \%$, respectively in the cefixime group and 66.67 , 30.07 , and $3.26 \%$, respectively in the amoxicillinclavulanate group $(p=N S)$.

\section{DISCUSSION}

The results of present study showed that cefixime is more effective than amoxicillin-clavulanate in resolution of cough, sputum production and clear CXR infiltration. CAP is the sixth most common condition cause of death with a highly variable prognosis, ranging from rapid recovery to life-threatening complications and death (Loddenkemper et al., 2003). Targeted, cost-effective treatments for CAP at the onset of disease can have a significant impact on the subsequent clinical and economic consequences. Therefore, continued efforts are being made to manage CAP patients, more efficiently and effectively in the outpatient setting. Choosing an antimicrobial agent that is the most cost effective, safe and specific to probable agents is encouraged (Niederman et al., 1998). The appropriateness of initial antimicrobial treatment has been shown to influence outcome in patient populations with severe disease (Rello et al., 2003).

Technical difficulties to separate typical and atypical microbes causing CAP in our hospitals such as many other centers are a limitation to choose accurate antibiotics. Due to lack of availability of respiratory fluoroquinolones, initial empirical antibiotic therapy for CAP is ceftriaxone + azithromycin and transition to oral therapy after clinical improvement.

According to Bjerre (2009) review, there is not enough trials to compare the effects of different antibiotics for 
Table 1. Baseline characteristics upon admission to the hospital in patients with CAP in Vali Asr Hospital of Arak.

\begin{tabular}{lccc}
\hline Parameter & Amoxicillin-clavulanate group & Cefixime group & P values \\
\hline Age (years) & $48.12 \pm 17.96$ & $50.0 \pm 14.73$ & 0.401 \\
Male $\mathrm{n}(\%)$ & $73(52.14)$ & $77(55.0)$ & 0.247 \\
& & & \\
Co-morbid illnesses (\%) & & & \\
Chronic obstructive pulmonary disease & $14(10)$ & $19(13.57)$ & 0.308 \\
Diabetes mellitus & $13(9.28)$ & $10(7.14)$ & 0.342 \\
High blood pressure & $26(18.57)$ & $21(15.0)$ & 0.310 \\
Congestive heart failure & $5(3.2)$ & $7(4.5)$ & 0.385 \\
Asthma & $2(1.31)$ & $3(1.9)$ & 0.50 \\
Opium addiction & $20(14.28)$ & $19(13.57)$ & 0.389 \\
Cigarette smoking & $30(21.43)$ & $37(26.43)$ & 0.412 \\
\hline
\end{tabular}

Data are presented as mean \pm SD or $\%$.

Table 2. Clinical status in first visit and 2nd and 4th week after drug administration in patients with CAP in Vali Asr Hospital of Arak.

\begin{tabular}{|c|c|c|c|c|c|c|}
\hline \multirow{2}{*}{ Parameter (\%) } & \multicolumn{3}{|c|}{ Amoxicillin-clavulanate group } & \multicolumn{3}{|c|}{ Cefixime group } \\
\hline & First visit & 2nd week & 4th week & First visit & 2nd week & 4th week \\
\hline Fever $(n)$ & $136(97.14)$ & $17(12.14)$ & 0 & $137(97.85)$ & $10(7.14)$ & 0 \\
\hline Cough (n) & $140(100)$ & $87(62.14)^{*}$ & $42(30.0)^{*}$ & $140(100)$ & $63(45.0)$ & $17(12.14)$ \\
\hline Sputum (n) & $140(100)$ & $51(36.43)$ & $25(17.86)^{*}$ & $140(100)$ & $42(30.0)$ & $13(9.28)$ \\
\hline Lung abnormal sounds (n) & 137(97.85) & $43(30.71)$ & $9(6.4)$ & 138(98.57) & $35(25.0)$ & $8(5.71)$ \\
\hline Leukocytosis (n) & $120(85.71)$ & $12(8.57)$ & 0 & $110(78.57)$ & $11(7.85)$ & $1(0.7)$ \\
\hline CXR infiltration $(n)$ & $137(97.85)$ & $119(85)$ & $49(35.0)^{*}$ & $135(96.43)$ & $114(81.43)$ & $27(19.28)$ \\
\hline
\end{tabular}

${ }^{*} p<0.05$, compared between two groups.

CAP and further trials are recommended. Young children are treated successfully with parenteral ceftriaxone followed by 8 days cefixime or amoxicillin-clavulanate (Amir et al., 1996) and cefixime is more effective but there is no significant difference between them. Cefixime is an extended-spectrum oral cephalosporin that can be prescribed once daily. Cefixime efficacy and safety in CAP treatment is compared with some other antibiotics (Quintilianii, 1996). Clinical success (cure or improvement) is observed in $94 \%$ of cefixime-treated patients and $79 \%$ for Co-amoxiclave group.

Although there was no significant difference between the two groups in overall outcome of CAP treatment but some advantages of cefixime such as once daily dosing and lower cost can suggest cefixime as the first line treatment for CAP in switch therapy in inpatients, especially in countries that are faced with drug option limitation. Of course, more trials concerning to outpatients population and cost-effectiveness are needed.

\section{ACKNOWLEDGMENT}

This article is the result of GP thesis and it is necessary to offer our thanks and appreciation to the Vice Chancellor for Research of the Arak University of Medical Sciences for providing the financial and logistical resources. We would also like to thank the very generous staff of the Vali-Asr hospital and the patients who participated in this clinical trial and gave us tremendous help and support in this study.

\section{REFERENCES}

Amir J, Harel L, Eidlitz-Markus T, Varsano I (1996). Comparative evaluation of cefixime versus amoxicillin-clavulanate following ceftriaxone therapy of pneumonia. Clin. Pediatr. (Phila). 35(12):629633.

Austrian R, Gold J (1964). Pneumococcal bacteremia with special reference to bacteremic pneumococcal pneumonia. Ann. Int. Med. 60:759-776.

Bjerre LM, Verheij TJM, Kochen MM (2009). Antibiotics for community acquired pneumonia in adult outpatients. Cochrane Database Sys. Rev. 4: CD112109.

File TM, Bartlett JG, Thorner AR (2011). Treatment of communityacquired pneumonia in adults in the outpatient setting. Up to date. 2012. Available from http://www.uptodate.com/contents/treatment-ofcommunity-acquired-pneumonia-in-adults-in-the-outpatient-setting?

File TM Jr, Tan JS, Plouffe JF (1998). The role of atypical pathogens: Mycoplasma pneumoniae, Chlamydia pneumonia, and Legionella penumophila in respiratory infection. Infect. Dis. Clin. North Am. 
12(3):569-592.

Loddenkemper R, Gibson GJ, Sibille Y (2003). The burden of lung disease in Europe: Why a European White Book on lung disease? Eur. Respir. Soc. J. 22(6):869.

Mandell LA, Wunderink RG, Anzueto A, Bartlett JG, Campbell GD, Dean NC, Dowell SF, File TM Jr, Musher DM, Niederman MS, Torres A, Whitney CG (2007). Infectious Diseases Society of America/American Thoracic Society consensus guidelines on the management of community-acquired pneumonia in adults. Clin. Infect. Dis. 44(2):S27-72.

Nicolau DP (2000). The Challenge of Prescribing Treatment for Respiratory Tract Infections. Am. J. Manage Care 6(8):419-428.
Niederman MS, McCombs JS, Unger AN, Kumar A, Popovian R (1998). The cost of treating community-acquired pneumonia. Clin. Ther. 20(4):820-837.

Quintilianii R (1996). Cefixime in the treatment of patients with lower respiratory tract infections: Results of US clinical trials. Clin. Ther. 18(3):373-390; Discussion 372.

Rello J, Bodi M, Mariscal D, Navarro M, Diaz E, Gallego M, Valles J (2003). Microbiological testing and outcome of patients with severe community-acquired pneumonia. Chest 123(1):174-180. 